\title{
STUDY OF THE MECHANICAL PROPERTIES FOR UNSATURATED POLYESTER REINFORCED BY NATURAL FIBERS
}

\author{
Bushra H. Musa, Rafah A. Nassif and Enass M. Hadi \\ Department of Applied Sciences, Material Science, University of Technology.
}

\begin{abstract}
Banana fiber at present is a waste product of banana cultivation. Moreover, without any additional cost input.

This study was carried out to investigate the effect of pseudo-stem banana fibers in the woven fabric configuration on the mechanical properties of unsaturated polyester composite. It was found that the addition of pseudo- stem banana woven fabric increased in the impact, compression, and flexural strength. The results showed that the impact strength on the pseudo- stem banana woven fabric reinforced (UP) composite is increased by $22 \%$ compared to virgin (UP), while flexural and compression strength on the composite is increased by $15 \%$ and $12 \%$ respectively.
\end{abstract}

Keywords: Banana fiber, unsaturated polyester, mechanical properties.

\section{Introduction}

Composite materials are becoming more embedded in today's products, and are used in many industries including aerospace, automotive, construction, and recreational (1). In the past decade, extensive research work has been carried out on the natural fiber reinforced composite materials in many applications. Natural fibers are available in abundance in nature and can be used to reinforce polymers to obtain light and strong materials. Natural fibers from plants are beginning to find their way into commercial applications such as automotive industries, household applications, etc. (2).

Natural fibers reinforced composites have received much attention due to their distinct advantages such as renewable source, biodegradability, high filling effect and nonabrasiveness. Because of tremendous changes in the quality of natural fibers, they are fast emerging as a reinforcing material in composites (3).

Bast fibers, like banana, are complex in structure. They are generally lingo- cellulosic, consisting of helically wound cellulose microfibrilsin amorphous matrix of lignin and hemicellulose. The cellulose content serve as a deciding factor for mechanical properties along with microfibril angle. A high cellulose content and low microfibril angle impart desirable mechanical properties for bast fibers.

Lignins are composed of nine carbon units derived from substituted cinnamyl alcohol; that is, coumaryl, conifery and syringyl alcohol. Lignins are associated with the hemicelluloses and play an important role in the natural decay resistance of the lignocellulosic material (4).

Laly et al. (5) have investigated banana fiber reinforced polyester composites and found that the optimum content of banana fiber is $40 \%$. The role of fiber / matrix interactions in chemically modified banana fiber composites were investigated using dynamic mechanical analysis and compared with those of untreated fiber composites by Sabu et al (6). It was reported that the dynamic modulus value and damping parameter used to quantify interfacial interaction in composites, increased dynamic modulus values and low damping value show the improved interactions between the fiber and matrix. Mariatti et al (7) studied the properties of unsaturated polyester reinforced with banana and pandanus woven fabric. The flexural and impact properties of both natural fiber composites are higher than pure polyester. Banana woven composites exhibit higher flexural and impact properties compared to that of pandanus woven composites.

The objective of this work is to study the impact strength, flexural strength, and compression properties of pseudo-stem banana fiber reinforced unsaturated polyester composite. 


\section{Experimental}

1.1 Preparation of banana fibers and matrix materials

The pseudo- stem banana woven fabric reinforced (UP) composite was prepared by the lay- hand method. The fibers are extracted from banana stems by hand and dried in sunlight for 12 hours until all the moisture is removed from the fiber. The dried fibers are made in the configuration of woven fabric. The matrix material was unsaturated polyester (UP) resin, the curing of (UP) was done at room temperature by the incorporation of 2 volume percent methyl ethyl ketone peroxide (MEKP). A $1 \%$ (volume percent) cobalt naphenate was added as a catalyst.

These materials were thoroughly mixed and stirred at low speed until it become uniform. The matrix material was poured into the mould slowly in order to avoid air trapping. The mixture was left for half an hour so that it becomes a little tacky. After that, the banana fiber woven fabric was laid on the matrix layer, which was covered by another layer of matrix by pouring the matrix slowly onto the surface of the fiber woven fabric. The three layered composite was cured at room temperature until it was dry. The same steps were used to make an unreinforced (UP) material.

The physical properties of banana fiber are given in Table (1).

\section{Mechanical Tests \\ Impact Test}

The charpy impact test on unnotched specimens was determined using (5 Jules) pendulum impact testing machine. The measurements dimensions of impact specimen were: length $55 \mathrm{~mm}$ and width: $10 \mathrm{~mm}$.

\section{Flexural and compression test}

All of these tests are carried out with the same scientific device. It is the hydraulic piston, its type is ley Bold Harris, No. 36110. The measurements dimensions of Flexural specimen was: length $15 \mathrm{~cm}$ and width: $3 \mathrm{~cm}$, while in compression was: length $6.66 \mathrm{~mm}$ and width: $3.6 \mathrm{~mm}$.

\section{Results and Discussion \\ 1. Impact strength}

The impact response in banana fiber reinforced (UP) composites reflects a failure process involving crack initiation and growth in the resin matrix, fiber breakage and pullout, delaminating and disbanding. Fig.(2) shows the impact strength values for virgin and banana fiber reinforced (UP), which are $9.86 \mathrm{KJ} / \mathrm{m}^{2}$ and $11.13 \mathrm{KJ} / \mathrm{m}^{2}$ respectively. The result of impact test showed that the banana fiber improved the impact strength properties of the virgin (UP) material approximately $22 \%$. The neat polyester sample shows low impact strength, Maries et al.(8) supposed that the main disadvantage of the thermoset moldings is high shrinkage during curing, brittle, and surface cracking. But on adding cellulose fibers, these drawbacks are almost eliminated. The fibers crowding leads to easy debonding at high loading which increases in the impact resistance.

\section{Flexural strength}

Fig.(3) shows the flexural strength of the virgin (UP) resin and pseudo- stem banana woven fabric reinforced (UP) composite. From the figure it can be seen that the flexural strength increased from $459.4 \mathrm{MPa}$ to $527.5 \mathrm{MPa}$ when banana woven fabric was used with (UP) material, this suggests that higher compatibility in composites is achieved, which lead to better stress transfer ability in composites. The stress transferred from one fiber to another through the matrix can be propagated without any failure to the composite. This enhances the strength of the composite (8).

\section{Compression test}

Fig.(4) shows the compression values for the virgin (UP) and pseudo- stem banana woven fabric reinforced (UP) composite, which are 95.5 $\mathrm{MPa}$ and $107 \mathrm{MPa}$ respectively. These values indicated that the compression increased by $12 \%$ in banana fiber reinforced composite. The development of strength in a composite depends on the existence of a strong interface, which can assure that the composite is able to bear load even after several fibers are broken because the load can be transferred to the intact portions of broken as well as unbroken fibers (9). 


\section{Conclusions}

1.The results of impact strength test showed that the pseudo- stem banana fiber improved the impact strength properties of the virgin (UP) material by approximately $22 \%$. Higher impact value leads to higher toughness properties of the material.

2.The compression strength increased when a banana woven fabric was used with (UP) material.

3.The flexural strength on the pseudo- stem banana woven fabric reinforced (UP) composite is increased by $15 \%$ compared to virgin (UP).

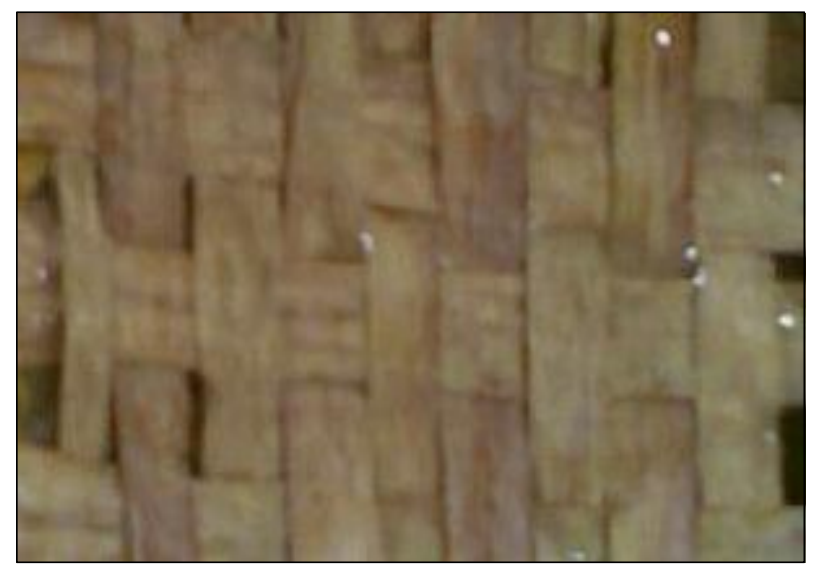

Fig. (1) : Pseudo- stem banana fibers in the woven fabric configuration.

Table (1)

Physical properties of banana fiber (5).

\begin{tabular}{|c||c||c||c||}
\hline $\begin{array}{c}\text { Tensile } \\
\text { strength } \\
\text { (MPa) }\end{array}$ & $\begin{array}{c}\text { Young's } \\
\text { modulus } \\
\text { (GPa) }\end{array}$ & $\begin{array}{c}\text { Elongation } \\
\text { at break } \\
(\mathbf{\%})\end{array}$ & $\begin{array}{c}\text { Density } \\
\mathbf{( g / \mathbf { c m } ^ { 2 } )}\end{array}$ \\
\hline 500 & 12 & 5.9 & 1.35 \\
\hline
\end{tabular}

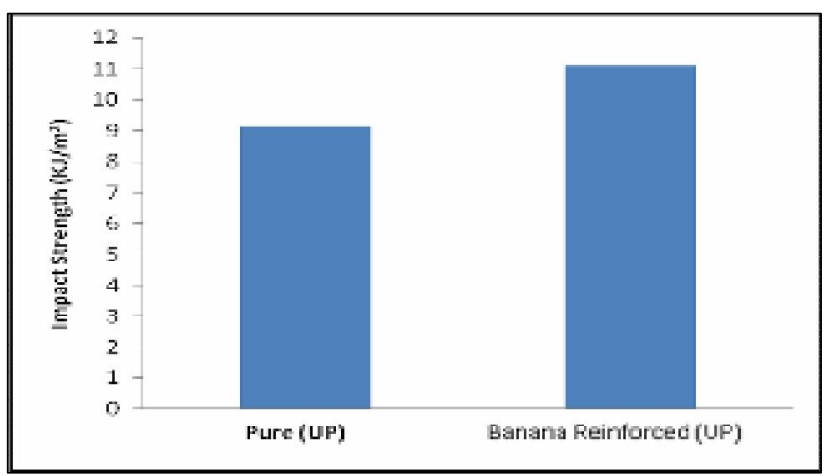

Fig.(2):Impact strength of virgin (UP) and banana fiber reinforced (UP) composite material.

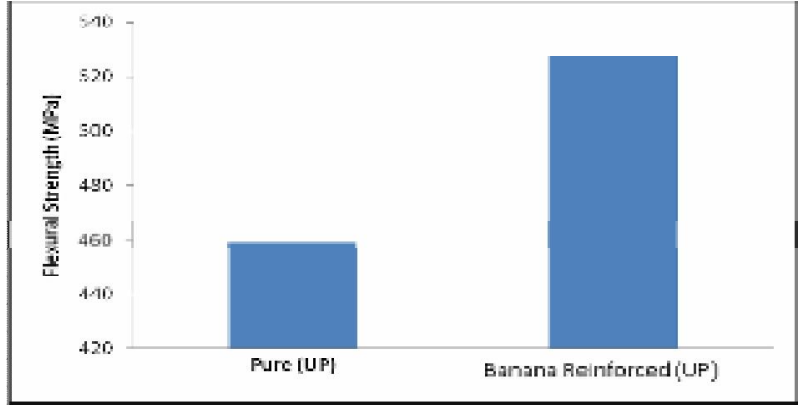

Fig. (3) : Flexural strength of virgin (UP) and banana fiber reinforced (UP) composite material.

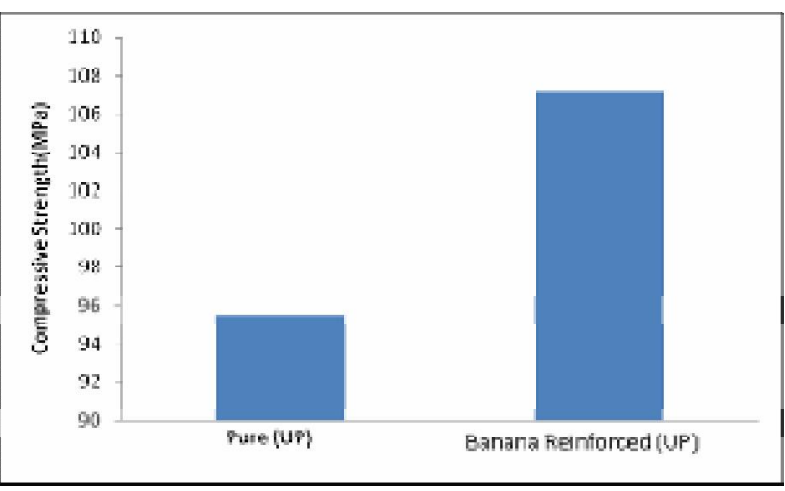

Fig.(4) : Compression strength of virgin (UP) and banana fiber reinforced (UP) composite material.

\section{References}

[1] D. M.Wilson,"The Implementation of Recycle Thermoset Composites in Thermoforming Molds",J. Industrial Technology, Vol.19,No.2, 2003.

[2] M.A.Malequ, et al.,"Mechanical Properties Study of Pseudo-Stem Banana Fiber Reinforced Epoxy Composite", The Arabian Journal for Science and Engineering, Vol.32, No.2B, 2007, pp.359363.

[3] K.Susheel and B.S.Kaith ,"Mechanical Properties of Phenolic Composites Reinforced with Flax-g- Copolymers Prepared Under Different Reaction Conditions -A Comparative Study" EJournal of Chemistry, Vol.5, No.1,2008, pp.177-184.

[4] M.Samrat, etal, "Banana FibersVariability and Fracture Behavior،" J. Engineering Fibers and Fabrics, Vol.3, No.2, 2008, pp.39-45.

[5] A.Laly,etal," Dynamic Mechanical Analysis of Banana Fiber Reinforced Polyester Composites",J. Composite 
Science and Technology, Vol.36, No.2, 2003, pp.283-293.

[6] A.Laly,etal." The Role of Fiber / Matrix Interactions on the Dynamic Mechanical Properties of Chemically Modified Banana Fiber / Polyester Composites", Composites part A: Applied Science and Manufacturing, Vol.37, No.9, 2006, pp.1260-1969.

[7] M.Mariatti,etal,"Properties of Banana and Pandanus Woven Fabric Reinforced Unsaturated Composites" J. Composite Material, Vol.42, No.9,2008, pp.931-941.

[8] I.Maris,etal,"A study of the Mechanical Properties of Randomly Oriented Short Banana and Sisal Hybrid Fiber Reinforced Polyester Composites", J. Applied Polymer Science, Vol.96, No.5,2005, pp.1699-1708.

[9] J.Maya and R.D.Anandjiwala "Recent Developments in Chemical Modification and Characterization of Natural Fiber Reinforced Composites", Polymer Composites, pp.187-297, 2008.

الخلاصة

ألياف الموز المستعملة هي نفايات زر اعية لنخيل الموز

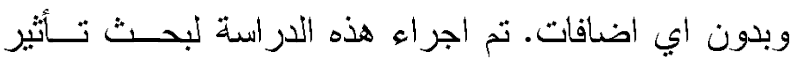

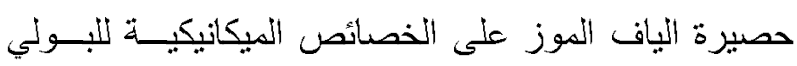

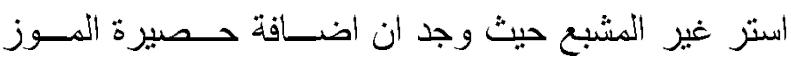

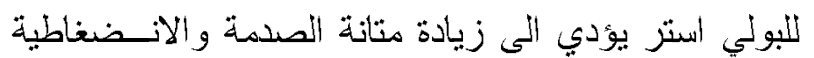

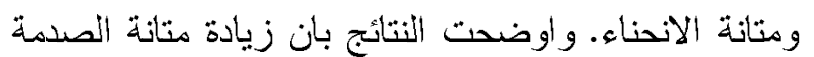

للمادة المتز اكبة كانت بحدود 20\% بينما كانت الزيادة فــي

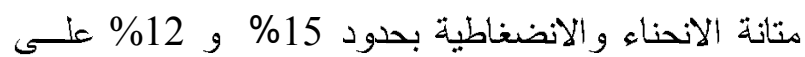
التو الي للمادة المتز اكبة مقارنة هع البولي استر الأنقي. 